\title{
Compromiso y distanciamiento: el sociólogo en su entorno social
}

\author{
Marta Núñez Sarmiento \\ Universidad de La Habana. Departamento de Sociología \\ La Habana. Cuba \\ mns@comuh.uh.cu
}

Data de recepció: març 2000

Data d'acceptació: gener 2001

\section{Resumen}

La autora reflexiona sobre el difícil balance que todo sociólogo debe establecer entre compromiso y distanciamiento, a partir de sus experiencias como socióloga comprometida. Resume sus reflexiones en cuatro aspectos: evitar el error de situarse «frente» a sus objetos de estudio; reconocer y analizar sus ideologías y las influencias que ejercen sobre su práctica investigativa; identificar conscientemente las coacciones a las que están expuestos los sociólogos, y evitar el error de cosificar y deshumanizar las figuras sociales, que integran sus investigaciones.

Palabras clave: compromiso y distanciamiento, coacciones del sociólogo, cosificación y deshumanización, sociólogos y sus objetos de estudio.

\section{Abstract. Involvement and Detachment: the Sociologist and her/his environment}

The author reflects upon the extremely useful and difficult balance which all sociologists must perform between involvement and detachment, based on her personal experiences as an «involved» sociologist. She summarizes four proposals: sociologists must avoid the mistake of placing themselves «above» the «objects» of their studies; they must acknowledge and analyse their ideologies, and be capable of understanding how they influence their research practice; social scientists should consciously identify the compulsions affecting them, and they must avoid dehumanising those social actors in their research.

Key words: involvement and detachment, compulsions during sociologic research, dehumanising of social actors during research, sociologists and research actors.

\section{Sumario}

1. Evitar el error de situarse, en tanto ser social, «frente» a los «objetos» de estudio

2. Reconocer y analizar cuál es la ideología del sociólogo y cuál es su influencia sobre su práctica investigativa

3. Reconocer conscientemente las coacciones a las que el sociólogo está expuesto
4. El sociólogo debe evitar el error de «cosificar», como entes independientes, a personas y agrupaciones que están interrelacionadas, y de "deshumanizar» a figuras sociales que forman parte de su investigación 
Te juzgarás a ti mismo, le respondió el rey. Es lo más difícil. Es mucho más difícil juzgarse a sí mismo que juzgar a los demás. Si logras juzgarte bien a ti mismo, es porque eres un verdadero sabio.

Antoine de Saint-Exupery, El principito

Reconocer que el sociólogo forma parte de la sociedad que estudia puede parecer una verdad de Perogrullo.

En este trabajo me he propuesto mirar críticamente esta afirmación, como estimo debe hacerlo todo científico social interesado en producir conocimientos realistas y, a la vez, sensibles a las realidades que desentrañan. Reflexiono acerca del compromiso y del distanciamiento, tomando los términos de Norbert Elias ${ }^{1}$, y reelaborándolos a partir de mis experiencias como socióloga «comprometida».

El compromiso lo entiendo como el acto en que el científico social incorpora a sus experiencias propias las representaciones ideológicas (no solamente las políticas) y las necesidades de las personas, los grupos humanos y las instituciones que investiga, y las comparte. El distanciamiento es la capacidad de este científico de "separarse cognoscitivamente» de las situaciones que estudia, incluida la habilidad de distanciarse de las ideologías de quienes analiza y que él mismo puede compartir, para observarlas críticamente. Construir conocimientos científicos en las ciencias sociales obliga al investigador a lograr un balance entre el compromiso y el distanciamiento.

Para elaborar este difícil saber, los sociólogos deben, en mi opinión, ser capaces de cumplir cuatro requisitos, que enumero a continuación:

1. Evitar el error de situarse, en tanto científicos sociales, «frente» a los «objetos» de estudio.

2. Reconocer y analizar cuáles son sus ideologías, y cuál es la influencia que ellas ejercen sobre su práctica investigadora.

3. Identificar conscientemente las coacciones a las que están expuestos.

4. Evitar el error de cosificar y deshumanizar las figuras sociales, que forman parte de sus investigaciones.

Explicaré cada uno de estos requisitos.

1. Norbert Elias. Involvement and Detachment. Basil Blackwell, 1987; Sociología fundamental, ver la introducción; el capítulo 2, «La sociología como cazadora de mitos», y el capítulo 5, «Interrelaciones de entramados: problemas de los vínculos sociales», Gedisa, 1995 (1 $1^{\text {a }}$ edición alemana, 1970). 


\section{Evitar el error de situarse, en tanto ser social, «frente» a los «objetos» de estudio}

El sociólogo tiene que reconocer que está condicionado por la sociedad en que vive, que, en el caso de los investigadores cubanos, suele ser la misma de las personas y situaciones que estudia. Así, las investigadoras cubanas que estudiamos el empleo femenino estamos inmersas y afectadas por esta problemática que analizamos. Por tanto, permeamos nuestras observaciones con las necesidades que emanan del hecho de ser trabajadoras. Menciono sólo algunas de ellas: las relaciones de poder con quienes nos dirigen, la capacidad de compra de los salarios y la doble jornada.

Los sociólogos deben comprender las diferencias que imprimen en investigadores e investigadoras las múltiples características socioeconómicas y sociodemográficas, que les tipifican, y las subculturas a las que pertenecen. $\mathrm{Me}$ refiero, entre éstas últimas, al barrio donde viven, las familias de donde provienen, las zonas geográficas de procedencia y las de su residencia en el momento del estudio. Ejemplifico con la investigación de las obreras agrícolas de Guanímar, un poblado ubicado a sesenta kilómetros al sur de La Habana, realizada en 1992 y $1997^{2}$. Las investigadas residían en ese pueblo, la mayoría procedía de familias asentadas largamente en ese lugar, y había otras que habían emigrado de las provincias orientales, su nivel de escolaridad promedio era de nueve grados concluidos, pero sus conocimientos reales manifestaban tener menor nivel, y eran, en su casi totalidad, obreras de primera generación por la vía materna. La investigadora residía en la capital, que era donde había vivido toda su vida, era universitaria, y su madre había trabajado como maestra.

Como regla, quienes investigan deben explicar a los investigadores sus características sociodemográficas y las subculturas de donde provienen, y no pensar que, al pretender mimetizarse con las personas que estudian, dejan atrás sus propios valores y necesidades.

Quiero mencionar un ejemplo negativo, porque también se aprende de este tipo de experiencia. En una investigación con textileras de la ciudad oriental de Santiago de Cuba en 1987, solicitada por la Federación de Mujeres Cubanas, las investigadoras procedíamos de La Habana. En ese momento se hablaba muy poco del tema de la violencia contra la mujer en Cuba, y no lo incorporamos en el programa del estudio. Sucedió que, una vez culminada la recogida de información, nos dimos cuenta que hubiera sido imprescindible abordar este problema, porque preocupaba a las textileras. Era, sin embargo, tarde para los plazos de la investigación, y nos quedamos con la conciencia culpable de haber sido incapaces de prever este problema.

2. Marta NúNEEz SARMiento, "La mujer en el período especial», revista América Latina, ed. Ciencia, Academia de Ciencias de Rusia, núm. 12, 1993, Moscú (en ruso); Las mujeres de la carreta, diciembre de 1993 (inédito); «Las mujeres de la carreta cinco años después (1992-1997)», ponencia presentada en el Encuentro "Las mujeres en los umbrales del siglo XXI», Universidad de La Habana, noviembre de 1997. 


\section{Reconocer y analizar cuál es la ideología del sociólogo y cuál es su influencia sobre su práctica investigativa}

Este aspecto está relacionado con los vínculos entre la sociología, el poder y las ideologías o los sistemas de creencias.

¿Los sociólogos son capaces de dirimir si en sus investigaciones seleccionan aquello que se corresponde con sus deseos y aspiraciones, y apartan de su interés aquello a lo que se oponen? ¿Admiten que lo que más les interesa es comprender cómo se relacionan entre sí los diferentes procesos sociales, cómo pueden explicarse, qué ayuda pueden ofrecer las teorías sociológicas en la orientación, explicación y en la solución práctica de los problemas sociales?

En lo que respecta al primer interrogante, cabe aquí nuevamente el ejemplo mencionado antes sobre nuestra incapacidad de reconocer de antemano el tema de la violencia doméstica.

Quiero comunicar otro ejemplo interesante, relacionado con los «encuentros de culturas diferentes» entre científicos sociales.

En una investigación realizada entre 1986 y 1989 con textileras de la fábrica Ariguanabo, auspiciada por la Federación de Mujeres Cubanas y una fundación norteamericana, en la que participaron cuatro investigadoras cubanas, dirigidas por la antropóloga norteamericana Helen Safa, sucedió que ésta última observó cosas que las cubanas no percibían, inmersas en la realidad que analizaban. Así, le llamó la atención que las obreras cubanas entrevistadas exigían más al Estado que a sus maridos para solucionar trabas de su «segunda jornada». Lo veía cuando estas mujeres manifestaban que prácticamente la única forma de solucionar el cuidado de los hijos en edad preescolar era que el Estado construyera más círculos infantiles. Safa argumentaba que casi ninguna de las 168 encuestadas se refirió a que sus parejas debían participar más en las tareas para atender a estos niños que no tenían acceso a estas instituciones preescolares. Las cubanas argumentaban que las obreras estaban en lo cierto.

¿Qué ocurrió aquí, aplicando la propuesta de balancear el compromiso con el distanciamiento? Las investigadoras cubanas sentimos, porque yo estaba entre ellas, que una extranjera, sobre todo de Estados Unidos, no podía comprender lo que ocurría en nuestro país. Aquí carecimos de la visión antropológica, y, también, nos sentimos «agredidas» ideológicamente en el terreno político. Este exceso de compromiso nos impidió constatar una realidad que pocos años después se evidenció fuertemente; sí existía un paternalismo estatal, que frenaba las iniciativas individuales para solucionar los problemas cotidianos como el cuidado de los niños más pequeños. En los años del «período especial», iniciado alrededor de 1990, en que la sociedad cubana ha sufrido un proceso de crisis y de reajustes, la participación creativa de los individuos ha sido una de las alternativas para sobrevivir.

Quiero referirme al segundo interrogante, el de la «intencionalidad ideológica» del investigador. Hay autores que afirman que el sociólogo debe ser capaz de liberarse de sus convicciones ideológicas, éticas, morales, para inves- 
tigar. Estimo que esto es imposible, porque los sociólogos viven con más o menos pasión sus realidades y, dentro de ellas, sus ideologías, como cualquier otra persona. La tarea del sociólogo consiste en aplicarse a sí mismo un autoexamen sobre su posición ideológica, y reconocer la necesidad de establecer un balance entre su compromiso con las situaciones que analiza y el imprescindible distanciamiento que debe establecer con respecto a esas situaciones.

Debe reconocer, asimismo, que cuanto más incontrolable sea para el sociólogo su actuar en un contexto determinado, tanto más «afectivo» será su pensamiento acerca de él. Y cuanto más afectivo, cuanto más cargado de fantasía sea su pensamiento sobre este contexto, tanto menor estará en condiciones de elaborar modelos adecuados para comprender científicamente el contexto dado, y más escasas serán sus posibilidades de intervenir en él para solucionar los problemas que ha detectado.

Traigo a colación nuevamente el ejemplo de los requerimientos que hacían las textileras de Ariguanabo al Estado, pensando esquivar los disgustos con sus parejas. Como explicaba, si las investigadoras hubiéramos insistido en nuestra negativa inicial a aceptar la visión "foránea» de la antropóloga norteamericana, no hubiéramos sido capaces de proponer las medidas que resumimos en las sugerencias finales del estudio. En ellas se reconocía la conveniencia de crear más instituciones estatales para aliviar el trabajo doméstico, pero se insistía, a la vez, en la pertinencia de que las mujeres, solas o con sus parejas, idearan vías para que todos los miembros de la familia compartieran las tareas de la segunda jornada. Esperar a que el Estado lo resolviera todo era una utopía que restaba independencia a las mujeres.

\section{Reconocer conscientemente las coacciones a las que el sociólogo está expuesto}

Los sociólogos, como todo miembro de la sociedad, están expuestos a múltiples coacciones. Y esto influye en el proceso de conocer a la sociedad. Hablaré de cuatro.

La primera forma de coacción es la que se aplica en ejercicios académicos. Se trata de las teorías que favorece un profesor o una comunidad científica, y que exigen que sus alumnos apliquen en sus exámenes, trabajos de curso y de diploma, tesinas de maestrías e incluso en tesis de doctorado. Ésta es una suerte de coacción del lenguaje científico, que cae en el dogmatismo cuando se niegan espacios a puntos de vista diferentes.

El segundo tipo de coacción es el que intenta imponer quien dirige las instituciones sometidas a investigaciones sociales, sobre todo para evitar que afloren los problemas. Para ello se suele coaccionar a investigados e investigadores. Los ejemplos de este tipo son casi infinitos: el director de una empresa que no accede a entregar informaciones abiertas a los investigadores, o que intenta decidir a quiénes entrevistar; directivos de instituciones que exigen conocer los nombres de aquellos subordinados que han opinado críticamente; diri- 
gentes que no aceptan las soluciones propuestas por los sociólogos, y que pueden llegar a frenar su aplicación.

Todo esto tiene que ver con las relaciones de poder en el quehacer sociológico. En lo que concierne al sociólogo, se trataría aquí de ejercer su libertad de pensamiento y su responsabilidad como científico social comprometido.

La tercera forma es la autocoacción. Al menos yo la vislumbro en quienes se autocensuran al elegir temas escabrosos a investigar, por temer enfrentarse a las coacciones descritas en el párrafo anterior. También las intuyo cuando los sociólogos no abordan problemáticas con enormes necesidades de aclarar científicamente, porque, por ejemplo, no podrían publicar los resultados.

Existe una cuarta coacción: la del poder que ejerce el sociólogo sobre quienes investiga. Pienso en la supuesta cualidad de las entrevistas abiertas para promover un "diálogo libre», a lo largo del cual fluyen "naturalmente» las opiniones de los entrevistados. Estas entrevistas son, realmente, procesos de comunicación unilaterales, en las que el entrevistador decide lo que le interesa escuchar, y el entrevistado habla unilateralmente, con más de monólogo que de diálogo.

Dentro de esta cuarta coacción sitúo la que ejerce el investigador cuando, consciente o inconscientemente, impone su ideología a quienes investiga. Esto impide «dejar hablar» a los investigados, sean personas, documentos o medios de comunicación audiovisuales.

Existe una especie de coacción de este tipo, en la que el científico social maneja su poder, cuando en el transcurso de la investigación, con fines de generar acciones o no, los investigados crean expectativas de que el sociólogo solucione sus problemas. Se genera, entonces, una dependencia de los investigados hacia el investigador.

\section{El sociólogo debe evitar el error de "cosificar», como entes independientes, a personas y agrupaciones que están interrelacionadas, y de "deshumanizar» a figuras sociales que forman parte de su investigación}

Este error conlleva a usar conceptos que, cuando guían una investigación, conduzcan a imaginar la sociedad de manera irreal o dividirlas en compartimientos estancos.

Cito dos errores de «irrealidad conceptual»: proponerse identificar al «cubano promedio» o a la "opinión promedio» o a sus aspiraciones, que pretenden resumir las encuestas de opinión.

En cuanto al sin sentido de dividir las realidades en compartimientos, apunto las intenciones fallidas de dividir cualquier sociedad en estudios sobre "familia», "violencia» y «empleo» sin relacionar cada uno de estos temas con su historia en cada país, o con las políticas sociales vigentes, o con las relaciones de los géneros, por mencionar sólo tres. 
Quiero mencionar otro ejemplo de «cosificación» y «deshumanización», por usar conceptos «mitos» que nada tienen que ver con las realidades de cada país. Sucede cuando se ha intentado imponer al análisis socioclasista de la Cuba actual las categorías de clases «obrera», "campesinos» e «intelectuales», sin incorporar en esta comprensión todas las diversidades de la realidad de hoy. Entre las realidades nuevas menciono un mayor número de personas empleadas en los servicios, las diversas formas de propiedad privada y cooperativa que se han introducido en la economía rural y en la urbana con los trabajadores por cuenta propia.

El sociólogo tiene que emanciparse de esta «metafísica de las figuras sociales», como ha dicho Norbert Elias.

Hay otra cara de esta moneda de «cosificar»y «deshumanizar». Sucede cuando el sociólogo desmitifica un proceso de este tipo que se ha producido en un segmento de la realidad que estudia. Esto sucedió en una investigación sobre la imagen turística de Cuba que han promovido empresas publicitarias cubanas. Se demostró que quienes la formularon construyeron imágenes que "cosificaban» y «deshumanizaban» la realidad turística del país. En este proceso quizá inconsciente, estas imágenes «fantasiosas» sustituyeron las imágenes turísticas de lo que realmente existe y de lo que desean ver los turistas que nos visitan o los potenciales a visitarnos. Ese estudio develó que las fotos y los textos contenidos en los materiales publicitarios trasmitían una población cubana excesivamente joven, blanca, vestida con ropas nuevas, y que se expresaba con frases impersonales, mientras que los lugares más visitados por los turistas aparecían vacíos, sin cubanos.

Los realizadores de esta publicidad proyectaron una imagen de «los cubanos» $\mathrm{y}$ «lo cubano» que se convirtió en un mito que mal representó una cosa y la otra.

Quiero retomar ahora unidos la cosificación y la coacción.

Cuando los sociólogos se someten a la coacción de los conceptos y métodos cosificados, que se han erigido en mitos, no necesariamente por los autores que los originaron, sino por quienes los dogmatizaron y los impusieron para comprender las realidades sociales, se sitúan por encima de esas realidades. Le dan vida a la dicotomía falsa del sujeto y del objeto. Esto pasa con Weber y sus conceptos de burocracia, legitimidad, carisma y Estado, así como con Marx y sus categorías de relaciones de producción, realidad material, acumulación ampliada de capital, enajenación e ideología. Es como si estos conceptos se refirieran a hechos extrahumanos, que funcionan a partir de una legalidad propia, situada más allá de toda acción humana.

Esta coacción con conceptos cosificados ha llevado, entre otras cosas, a decir que el marxismo ha muerto. Quienes apoyan esta posición no conciben que el marxismo, como ciencia social de enorme compromiso político, pasa en estos momentos por un momento de corte epistemológico, de repensarse a sí misma, con ojos propios y de los «otros», porque también se ha visto convulsinada por las intensas sacudidas de las sociedades de fines de este siglo. La existencia de estos ciclos de crisis a lo largo de la historia del pensamiento social ha sido reconocida por los pensadores más lúcidos, desde Carlos Marx en su sin- 
tética introducción a la Contribución a la crítica de la Economía Politica (1857) hasta el sociólogo norteamericano Smelser en una reciente conferencia impartida en la Universidad de La Habana.

Pensaré a sugerir doce «antídotos» para evitar cargar la mano en uno de los polos de esta dicotomía del compromiso y el distanciamiento.

1. Los investigadores deben dedicar más tiempo dentro de la investigación a pensar sobre la «vigilancia epistemológica», término que tomo de Pierre Bourdieu. Consiste en planificar espacios individuales y colectivos a lo largo del programa de la investigación para meditar críticamente cómo nos hemos aproximado a nuestro objeto de estudio. Estos momentos de reflexión metodológica los ha insertado muy bien en el momento del trabajo de campo la metódica de la «evaluación rural rápida» (Rural Rapid Appraisal), promovida inicialmente por el británico Robert Chambers ${ }^{3}$. Según este procedimiento, cada día que se recoja información hay que planificar igual cantidad de tiempo para aplicar los instrumentos del estudio y para reflexionar sobre cómo transcurrió este proceso. Y hay que hacerlo en el mismo día. Yo añado la conveniencia de escribir un diario de observación sobre el quehacer de los investigadores que incluya pensamientos de cómo «corren» los instrumentos cuando se les aplica a la realidad «real».

En una observación participante que realicé entre obreras cargadoras de ladrillos o «tejareras» en La Habana en $1989^{4}$, yo debía hacerles leer dos artículos que la periodista Mirta Rodríguez Calderón había publicado en la revista Bohemia sobre la violencia doméstica. Perseguía que ellas leyeran estos materiales y los discutieran grupalmente. Inicialmente pensé emplear la vía tradicional de los murales, que existen en todos los centros de trabajo. Pero mientras cargaba ladrillos con las obreras observé que una de las maneras en que descansaban durante la jornada laboral era alejándose por unos cinco minutos de la línea de producción, para leer letras de canciones (boleros o corridos mexicanos), que habían escrito en una libreta. Ideé pegar esos dos artículos en una libreta y pasar este cuaderno entre las mujeres. Resultó un medio mucho más eficaz que el que había pensado al principio, porque se parecía a lo que ellas hacían habitualmente.

2. Hay que emplear más la interdisciplina. Trabajar en equipo multidisciplinario ofrece una variedad de enfoques, que permite reconstruir las situaciones tal y como operan en la realidad. Es aconsejable que cada especialista ejerza y practique su disciplina al estudiar la realidad concreta, y evitar las tendencias a lo que denomino el «síndrome del juguete nuevo». Con esto me refiero a las ansias que, a veces, se despiertan en los investigadores que trabajan en equipo de irrumpir en el campo de otros, dejando a un lado el hecho de ejercer su propia disciplina. Los involucrados en estos equipos

3. Robert Chambers, Rural Research, Cambridge University Press, Londres, 1985.

4. Marta NúNÉz SARMiENTO, Mujeres en empleos no tradicionales, Editorial Ciencias Sociales, La Habana, 1991. 
deben practicar conscientemente este aspecto de la vigilancia epistemológica.

Otra forma de aplicar un enfoque interdisciplinario es cuando un investigador consulta obras de disciplinas cercanas a la suya, y que le amplían su comprensión de los fenómenos que analiza. Lo he hecho con la historia del empleo en Cuba, al comparar la obra de José Antonio Saco Papeles sobre la Vagancia en Cuba (1837) con las actitudes de las cubanas en el proceso laboral de hoy. O con La Fidelísima Habana, de Gustavo Eguren, obra en la que el autor recopila documentos de la Corona española entre 1508 y 1898, que reproducen su mirada hacia los criollos de Cuba. Me ha servido de mucho para reconstruir una mirada histórica y casi antropológica de la psicología social de los cubanos, para tratar de explicar cómo somos hoy. Recomiendo usar la literatura contemporánea, que apunta fenómenos de la actualidad, que aún las ciencias sociales no han podido explicar.

3. Los investigadores deben ser más electivos cuando escogen sus paradigmas en el caudal teórico y metodológico. Aquí los cubanos podemos seguir la tradición «electivista» iniciada por José Agustín Caballero hace dos siglos. Todos tenemos que reflexionar más antes de asumir los conceptos científicos «aceptados» sobre regularidades sociales. Traigo a colación la propuesta de la norteamericana Judith Butler en su Bodies that Matter ${ }^{5}$, cuando afirma que la tradición del lenguaje nos ha legado dos géneros, el femenino y el masculino, ocultando la existencia del homosexual.

4. Se debe conocer mejor la sociedad en que se vive, en términos de la nación y su entorno mundial, para racionalizar con más precisión dónde y en qué época vivimos. Y las posiciones que adoptamos en ella.

5. Sugiero invitar a un psicólogo, para que controle las relaciones entre los investigadores y los investigados, y que no esté inmerso en la dinámica de la investigación. Este profesional ayudará a que los investigadores se analicen a sí mismos.

6. Otra sugerencia para acercarnos al balance entre el compromiso y el distanciamento, es usar las reflexiones de investigadores foráneos, que hayan estudiado realidades similares a las que nos enfrentamos. Esto se puede lograr leyendo sus obras, trabajando junto a ellos en un equipo que analice una misma realidad, o haciendo comparaciones a distancia, en las condiciones en que cada uno analiza su objeto. Expongo un ejemplo: la norteamericana Arlie Horchschild, en su libro The Second Shift (1989) ${ }^{6}$, afirma que la mujer en Estados Unidos ha sufrido una "revolución detenida» (stalled revolution). Esto es, las mujeres evolucionaron mucho en los sesenta y los setenta, mientras que la sociedad, en su conjunto, quedó atrás. Esta propuesta me sugirió

5. Judith BuTLER, Bodies that Matter, «Preface», «Introduction», Routledge, Nueva YorkLondres, 1993.

6. Arlie Horchschild, The Second Shift, Avon Books, Nueva York, 1989. 
una hipótesis para comprender la evolución del empleo femenino en Cuba entre 1959 y la actualidad: la tendencia observada en estos años en que la mujer se incorporara al empleo de manera estable, ascendente hasta 1989 y sin grandes retrocesos durante los años de crisis y reajustes hasta la actualidad, se debe a que la sociedad cubana también se revolucionó. No ha ocurrido en nuestro caso una «revolución detenida».

7. Practicar la «investigación participativa» desde el diseño hasta la discusión del informe final también ayuda a resolver el dilema del compromiso y el distanciamiento. Habría aquí que informar constantemente a los investigados de lo que observa el investigador, y retroalimentarse éste con los puntos de vista de aquéllos.

8. Propongo que los investigadores organicen entre sí los análisis grupales para «sacar» la subjetividad intrínseca de cada uno de ellos con relación al tema que estudian. Las investigadoras feministas suelen practicarlo mucho, como una forma de ser honestas con ellas mismas y con quienes investigan. Los sociólogos solemos investigar a personas de grupos sociales diferentes a los grupos sociales a los cuales pertenecemos. Indagamos todo lo posible sobre sus vidas, pero conocemos poco de las vidas de cada uno de los investigadores. Nunca contamos nuestras «historias». Hacerlo contribuiría a no imponer las percepciones propias de los investigadores a las personas que investigan. Pienso en dos ejemplos. Uno es el de la persona que elige el tema de la violencia doméstica, porque fue objeto de ella en algún momento de su vida. Esta elección es totalmente válida, pero tiene que acompañarse de análisis que aseguren que el investigador no proyectará sus experiencias en su programa de investigación. El segundo ejemplo lo extraigo de mi experiencia. Me «enamoré» hasta tal punto de la investigación de las mujeres del pueblo de Guanímar, que sólo cuando mis colegas del Departamento de Sociología de la Universidad de La Habana me preguntaron si no había prácticamente agotado este tema, teniendo en cuenta que no contaba con los recursos materiales para trasladarme a ese poblado y mantener mi docencia universitaria, que decidí emprender el estudio de las mujeres profesionales. En Guanímar me dedico en estos momentos a supervisar las acciones que resultaron de varios años de investigación.

9. El sociólogo debe reconocer que es cómodo «amoldarse» a la coacción del lenguaje sociológico científico «aceptado», incluso en la esfera de los métodos. Digo que es "cómodo", porque "otros», con una experiencia mayor, lo escribieron. Aquí es preciso ejercer la vigilancia epistemológica: no se puede ver solamente la coacción en la coacción de las personas (profesores, funcionarios, instituciones) sobre nosotros, sino en la coacción que el lenguaje científico ejerce sobre nosotros, quienes accedemos a ello y lo alimentamos. Puede darse este caso cuando nos aferramos a iniciar un programa de investigación siguiendo los pasos de «objetivos», "problemas», «hipótesis», "conceptos», «selección de muestras», «elección de instrumentos. 
Estimo que un estudio puede comenzar por una hipótesis. Éste es el caso si deseo comprobar que las mujeres profesionales se han erigido ya en Cuba en las proveedoras principales de los ingresos de sus hogares, por encima de sus parejas. O puedo comenzar por redefinir el concepto de poder, al menos en el terreno del empleo femenino.

Sugiero aquí acceder más a la autorreflexión y a la reflexión en grupos de discusión entre los investigadores.

10. Es preciso recordar constantemente que hay que «hacer hablar» a quienes investigamos, para comprender las situaciones que estudiamos tal y como ellas son, y no como nosotros las pensamos. Cuando investigué a las obreras agrícolas de Guanímar en 1992, en pleno período especial, y en momentos en que se intensificaban los cultivos de hortalizas de ciclos cortos para intentar abastecer de alimentos a la población y suplir los déficits enormes en las importaciones alimentarias, observé un proceso peculiar entre ellas. Por primera vez consechaban verduras que nunca habían incorporado en sus dietas cotidianas: las berenjenas, la col, la zanahoria. ¿Cómo las comían? Cocinándolas con azúcar y amoldadas en pequeñas bolitas, el «dulce de fruta bomba de berenjena» y la "col en almíbar». Si no hubiera estado entrenado para dejar correr la imaginación de los «otros», este fenómeno hubiera pasado inadvertido.

11. Ante las coacciones, el sociólogo debe practicar su libertad de pensamiento, ampliar su cultura sociológica y tener presente su responsabilidad como científico social comprometido.

12. Por último, emplear varias técnicas y métodos para recoger y analizar la información contribuye a acercarnos al balance entre compromiso y distanciamiento. Sugiero, por ejemplo, comenzar por una observación participante, que enriquezca la visión del investigador sobre el fenómeno, y que facilite el rapport con las personas que desea conocer con mayor profundidad. El investigador podría después, o simultáneamente a la observación, aplicar el análisis de contenido a los medios de comunicación para reconstruir cómo reflejan los procesos que analiza y cuáles son los mensajes que más penetran en los investigados. Esto suelo hacerlo en mis estudios con obreras cuando analizo qué les llama más la atención de las telenovelas cubanas y extranjeras que proyecta la televisión durante la investigación. También sugiero reconstruir los perfiles socioeconómicos y sociodemográficos de las personas estudiadas hurgando en las nóminas de pago de los centros de trabajo, en las planillas de las oficinas de recursos humanos, y en los inapreciables controles estadísticos que llevan los médicos de la familia. Después de aproximarse a la situación bajo análisis por las vías que he enumerado, es más fácil aplicar las encuestas, las entrevistas en profundidad y las historias de vida. Por supuesto, cada uno de estos métodos se aplica a submuestras dentro de la muestra mayor que se sometió a la encuesta. 